\title{
Joint Agglomeration of Phosphate Fines and Manganese Ore with Coal Mining Waste
}

\author{
A.S. TLEUOV, S.T. TLEUOVA, S. K. ISKAKOVA, \\ O.K. BEISENBAYEV, ZH.M. ALTYBAYEV and U. NAZARBEK \\ M.Auezov South Kazakhstan State University \\ Shymkent, Tauke khan avenue, 5, Republic of Kazakhstan160012 \\ ${ }^{*}$ Corresponding E-mail: arsenal_575@inbox.ru \\ http://dx.doi.org/10.13005/ojc/320225
}

(Received: February 09, 2016; Accepted: March 15, 2016)

\begin{abstract}
The small concentrates which are turning out as a result of enrichment from ores of iron, nonferrous and other metals, as a rule, are unsuitable for direct use in melting or in other technological processes. Complex and rational use of mineral raw materials, fuel and energy resources is an actual problem in the industry of Kazakhstan. The development of domestic manganese ore and the expansion phosphorus manufacturing become particularly urgent. To improve raw material and fuel energy displays there was set a goal of using waste of different enterprises including fine fraction of phosphorus and manganese ones, and also waste coal as fuel. The use of these wastes allows for phosphoric subsector to obtain fluxed phosphorus sinter and out of it yellow phosphorus and ferrophosphorus with an increased content of manganese. In this regard, organization of complex production of phosphate sinters with the usage of manganese ore and mining waste undoubtedly is of particular interest. The ferrophosphorus obtained after electrothermic processing can be used as an alloying element in steel smelting as contains a significant content in the manganese. In the given research as the solid fuel are applied coal waste of Lenger deposit recycling of which is possible by increasing the extent of their use. It should be said that the level of waste coal is extremely low as yet. Using coal mining waste in the chemical and metallurgical industries is highly effective for replacing a flux component and reducing the cost of expensive coke. Here are the research results of the joint agglomeration of phosphate and manganese ores with use of coal waste as a fuel. To determine the optimal process conditions the method of mathematical planning of experiments is used. It has been found that an increase in manganese ore in the sintering mixture contributes to the strength of the sinter, and increase in coal mining waste reduces the strength of the sinter.
\end{abstract}

Keywords: Manganese ore, Mathematical planning of experiments, Agglomeration, sinter, sinter mixture, coal mining waste.

\section{INTRODUCTION}

In the Republic of Kazakhstan, as well as throughout the world, extracted minerals tend to decrease in quality deterioration and technological properties. We have to admit that the rich easily enriched ores deplete, and replenishment of raw materials takes place at the expense of inclusion of 
more poor, refractory raw materials ${ }^{1-3}$. The feature for the Republic of Kazakhstan is the fact that its existing today mining complexes are usually formed on the basis of large rich fields such as Zhezkazgan copper, Sokolov and Sarbai iron and polymetallic deposits in Eastern Kazakhstan, etc. These deposits have been actively exploited for decades, and today their stocks are largely worked out ${ }^{[4-6]}$. Efficient ore processing technologies, relatively poor in content of useful components, as well as substandard raw materials are not still well developed today, especially for the conditions of remote shift enterprises.

As Kazakhstan is a republic with a highly developed mining industry, which for decades has carried out the extraction and processing of mineral raw materials, a huge amount of technogenic mineral formations has been accumulated on its territory. In rock dumps gets much of the geological exploration of recorded industrial raw materials, as process losses foreseen by mining companies' projects reach $10-15 \%$ of the proven reserves in the fields of simple structure and up to $30-50 \%$ on deposits (or sites) of complex structure ${ }^{7,8}$.

Kazakhstan has a number of fields of rather poor manganese ores. Exceptions make Ushkatyn-3 with a considerable reserve of oxidizing and oxide ores $^{1,9}$. Large Ktai minefield also refers to a type of layered volcanic sedimentary metamorphosed deposits. Ore deposit is a complex layer-like body. Rich hematite layer thickness is about $20 \mathrm{~m}$. There are two layers of manganese ore. There are also poor iron and ferromanganese ores. Rich ores contain $53 \%$ of iron, $0.7 \%$ of manganese, $0.17-0.74 \%$ of sulfur, $0.03 \%$ of phosphorus, and up to $0.015 \%$ of arsenic. Rich ores can be used without enrichment. Rich ore reserves are about 20 million tons, and the poor, with an average iron content of $31.2 \%$ is about 60 million tons. Manganese ore deposit East Kamys located in Zhanaarkinskii district of Karaganda region is being developed by "Kazmarganets"10.

Balance reserves of manganese ore at the East Kamys deposit are concentrated in three ore bodies. Ore deposits in this field are on the ground at a depth of zero to $5 \mathrm{~m}$, their length is from 500 to $650 \mathrm{~m}$, the angle of gradient is $60-90$ degrees, and thickness from 0.5 to $35 \mathrm{~m}$ with an average of $5-8 \mathrm{~m}$. In ore East Kamys field two main types of geological and industrial manganese ores are developed: oxidized (for open pit), which account for $52 \%$ of the approved reserves of the deposit, and the primary (for underground mining).

\section{MATERIALS AND METHODS}

Composition and preparation of raw material. Technological scheme of manganese ores preparation to metallurgical processing determines the formation of small things, the significant content of which has accumulated at mine sites and processing plants. Modern metallurgical aggregates are adapted to consume only the lump materials. To be engaged in ferro-alloys production, manganese ore fines needs to be charged ${ }^{11,12}$.

A special place in complex ferrous alloys is occupied by a ferro-alloy containing $\mathrm{Fe}, \mathrm{Si}, \mathrm{Mn}$, especially phosphorus. Phosphorus increases the corrosion resistance, cast ability of steel, reduces the loss of steel, and eliminates the stickiness of the sheets during the rolling process. Manganese is also a commonly used alloying element. Within creasing content of manganese in the steel, its harden ability, hardness, tensile strength, and fluidity limit increase, while viscosity decreases. Silicon has greater affinity for oxygen, as for the reaction $\mathrm{Si}+\mathrm{O}_{2}=\mathrm{SiO}_{2} \Delta \mathrm{G}$ it is minus $576,0 \mathrm{~kJ} / \mathrm{mol}$. Therefore, it is used as a deoxidizer. Tool steels contain up to $0,37 \% \mathrm{Si}$, and doped up to $5 \% \mathrm{Si}$. Silicon increases the hardness, fluidity limit, tensile strength of steel, and reduces its viscosity. Silicon steel is widely used for springs and spring tides. Siliceous transformer iron (about 4\% Si) has low watt losses. Manganese has a relatively high sulfur tool to sulfur, thus, $\Delta G$ for reaction $\mathrm{Mn}+1 / 2 \mathrm{~S}_{2}=\mathrm{MnSis}$ minus $157,1 \mathrm{~kJ} / \mathrm{mol}$. Therefore, when a steel additive, neutralizes the harmful effects of sulfur ${ }^{13}$.

The process of formation of high silicon ferrophosphorus in the light of the above data can be represented as follows. The reduction takes place in the coke zone of $\mathrm{P}_{2} \mathrm{O}_{5}$ and $\mathrm{SiO}_{2}$. A little bit earlier reduced iron flows inform of droplets and dissolves phosphorus and silicon, facilitating the recovery of silicon from silica. The amount of silicon in ferrophosphorus depends on the conditions of the silica recovery process (during the hot oven and an overvalued coke excess, this amount is great). With 
the passage of droplets through the slag, silicon is oxidized. In coke zone both processes occur simultaneously, under it oxidation of silicon ends in accordance with the amount of $\mathrm{P}_{2} \mathrm{O}_{5}$ in the slag. Since ferrophos accumulates in the furnace within one or two days, and all this time it is washed in a big amount of slag, the oxidation of silicon is only stopped after its distribution between the slag and the metal is established. To conduct the research, phosphorite fines from Novo Dzhambul Phosphate Plant of LLP "Kazphosphate", manganese ore from deposits Zhomart (Zh) and West Kamys (WK), coke fines and coal waste of Lenger coals (LT) were used as initial components. Chemical composition of raw materials is shown in Table $1^{14,15}$.

Lenger coal waste was formed during the mine extraction of coal. Conducted physical and chemical analyzes have shown that the carboncontaining wastes are carbon-containing rocks with low carbon content. While sintering coal mining waste serve as a fuel component and quartz-containing material As manganese and iron component, substandard manganeseè ores are used.
The method of statistical design of experiments. To search for the optimal conditions of agglomeration of phosphorite mixed with manganese ores, we applied the method of planning of experiments ${ }^{15,16}$.

Underlying the methods of statistical design of experiments is the use of an ordered plan of points' distribution (the input parameters of experiments) in the factor space and the use of a new dimensionless coordinate system.

Under the factors, we understand inputs. In the experiment, the factors must take strictly defined values levels, we used experimental design on two levels, defining the values of $\mathbf{Z 1}$ and $\mathbf{Z} 2$ for the upper and lower range of the research.

In the methods of experimental design, we used coded (dimensionless) parameters. They correspond to the transfer of the coordinate origin to the point - the center of the plan (main level), origin to the point $z_{j}^{0}$ - the center of the plan (main level),

Table 1: Chemical Composition of Raw Materials, \%

\begin{tabular}{|c|c|c|c|c|c|c|c|c|c|c|}
\hline Component & $\mathrm{P}_{2} \mathrm{O}_{5}$ & Mn & $\mathrm{SiO}_{2}$ & $\mathrm{CaO}$ & MgO & $\mathrm{Fe}_{2} \mathrm{O}_{3}$ & $\mathrm{Al}_{2} \mathrm{O}_{3}$ & C & $\mathbf{S}$ & $\mathrm{H}_{2} \mathrm{O}$ \\
\hline Phosphorite (fines) & 21,2 & 0,05 & 24,1 & 36,8 & 2,2 & 1,7 & 1,6 & - & & 0,7 \\
\hline $\begin{array}{l}\text { Manganeseore fines } \\
\text { Zhomart }\end{array}$ & 0,032 & 33,4 & 11,3 & 7,9 & 1,5 & 11,2 & 3,3 & 10,3 & 0,02 & \\
\hline $\begin{array}{l}\text { Manganese ore } \\
\text { fines West Kamys }\end{array}$ & 0,034 & 24,0 & 40,2 & 1,4 & 1,0 & 4,8 & 4,9 & 10,7 & 0,02 & \\
\hline Coke fines & - & - & 4,9 & 1,5 & 0,4 & 2,2 & 1,8 & 86,0 & 0,8 & 1,1 \\
\hline Lenger coal waste & - & - & 35,8 & 2,1 & 0,3 & 3,3 & 8,0 & 18,6 & & 6,8 \\
\hline
\end{tabular}

Table 2 . The Range of Variation of Independent Factors

\begin{tabular}{|c|c|c|c|c|c|c|}
\hline \multirow[t]{2}{*}{ Factors } & \multicolumn{3}{|c|}{ Coded form } & \multicolumn{3}{|c|}{ Natural form } \\
\hline & $x_{1}$ & $x_{2}$ & $x_{3}$ & Zh & WK & $\mathbf{L T}$ \\
\hline Lower level & -1 & -1 & -1 & 24,1 & 7,02 & 6,33 \\
\hline Upper level & +1 & +1 & +1 & 35,9 & 12,97 & 13,67 \\
\hline Zero level & 0 & 0 & 0 & 30 & 10 & 10 \\
\hline Shoulder+ 2 & $+1,68$ & $+1,68$ & $+1,68$ & 40 & 15 & 16 \\
\hline Shoulder- 2 & $-1,68$ & $-1,68$ & $-1,68$ & 20 & 5 & 4 \\
\hline
\end{tabular}




$$
z_{j}^{0}=\frac{z_{j}^{\max }+z_{j}^{\min }}{2}, j=1,2 . k
$$

Interval of variation along the axis ${ }^{z_{j}}$, is given by the formula:

$$
\Delta z_{j}^{\prime}=\frac{z_{j}^{\max }-z_{j}^{\min }}{2}
$$

For the transition from the physical (natural) variables ${ }^{z}$ to dimensionless coordinates we use the expression:

$$
x_{j}=\frac{z_{j}-z_{j}^{0}}{\Delta z_{j}},
$$

For the dimensionless variables the upper level ${ }^{x_{j}}$ of the coded coordinates equals to +1 , and the bottom level to 1 , the coordinates of the center of the plan is zero. In some plans (see below) dimensionless factor values $x_{j}= \pm \alpha$ are used; the corresponding values in the natural coordinates are found by the expression:

$$
z_{j}=z_{j}^{0}+\alpha * \Delta z_{j}
$$

Orthogonal planning of experiment. Full factorial experiment requires experimentation with all possible combinations of factors at all levels of variation. With two factors and two levels, 4 experiments are needed. This is the minimum number of experiments to determine the parameters of linear mathematical model. Getting a more complex model requires additional experiments.

To reduce the number of experiments we used the orthogonal experimental design (Box-Wilson plan). This method allows to reduce the number of experiments, and to simplify the mathematical treatment of experimental results. For the construction of orthogonal central composite designs, the so called star shoulder $\alpha$ (shoulder of star points) is used. For two factors $\alpha= \pm 1,682$ (in the coded scale) ${ }^{17,18,19}$.
As a result of mathematical processing of experimental results, the coefficients $b$ of mathematical model describing the object of study in the form of the regression equation is determined:

$Y_{R}=b_{0}+b_{1} * X_{1}+b_{1} * X_{1}^{2}+b_{2} * X_{2}^{3}+b_{1} * X_{1} * X_{2}$,

where $Y_{R}$ is the estimated value of the output.

Evaluation of the significance of the coefficients of the regression equation (usually using Student test (criterion), with insignificant coefficients are assumed to be zero, which simplifies the form, and further usage of the mathematical model. In addition, the validation of the mathematical model was performed using the Fisher criterion.

For practical use of the mathematical model, for example to find the optimal mode, recalculation of the model for the natural scale of the input variables is done in the expression (3):

$X_{1}=\frac{Z_{1}-Z_{1}^{0}}{\Delta z_{1}}$ and $X_{2}=\frac{Z_{2}-Z_{2}^{0}}{\Delta z_{2}}$

After that, we get the equation:

$Y_{R}=\grave{a}_{0}+\grave{a}_{1} * Z_{1}+\grave{a}_{2} * Z_{2}+a_{1} * Z_{1}^{2}+a_{2} * Z_{2}^{2}+a_{\mathrm{r}} * Z_{1} * Z_{2}$,

where $Z_{1}$ and $Z_{2}$ are substituted by the real value of the input in the range from- $\alpha$ to $\alpha$.

To automate the processing of the results, we developed a special program for the Personal Computer based on Ms Excel system and used among Ms Windows XP systems. The program allows for the dialogue to get necessary results of calculations and provide a search for the best mode of the process. In conducting experiments the independent factors were:

- $\quad$ The amount of ore at Zhomart deposit (Zh), $\%$ by weight of phosphate fines $\left(X_{1}\right.$ is a coded form, Zhis a natural form);

- $\quad$ The amount of ore at West Kamys deposit (WK), \% by weight of phosphate fines $\left(\mathrm{X}_{2}\right.$-is a coded form, the WK is a natural form); The amount of Lenger coal mining waste (LT), \% by weight of phosphate fines $\left(X_{3}\right.$ is a 
coded form, LT is a natural form). The output parameters were: strength of sinter, $\mathrm{MPa}$; output of useful sinter, \%.

\section{RESULTS}

In experiments remained constant parameters: number of phosphorite and coke $(10 \%$ by weight of the phosphorite). The ranges of variation of independent factors are shown in Table 1, the plan for the experiments and their results are shown in Table 2. in Table 3

Plan and results of experiments are given

Based on the data in Tables 2,3 the following regression equations were obtained: For the strength of sinter.

Sinter strength $=1,8664+0,25 \mathrm{x}_{1}-0,273 \mathrm{x}_{2}-0,12 \mathrm{x}_{3}+0,0544 \mathrm{x}_{1}^{2}$ $-0,0217 x_{2}-0,0128 x_{3}-0,0065 x_{1} x_{2}-0,1937 x_{1} x_{3}+0,1962 x_{2} x_{3}$;
Sinter strength $=1,9116+0,042 \mathrm{Zh}-0,2118 \mathrm{WK}$

$+0,0748 L T+0,0016 Z h^{2}-0,0024(W K)^{2}-$

$-0,001(L T)^{2}-0,000 Z h W K-0,0089 Z h L T+0,0179 W K L T$;

For the output of sinter

Sinter output $=55,387+5,5874 x_{1}-4,69 x_{2}-5,148 x_{3}$

$-6,128 x_{1}^{2}-4,888 x_{2}^{2}-2,23 x_{3}^{2}+0,0 x_{1}^{1} x_{2}-0,25 x_{1} x_{3}+8,75 x_{2} x_{x 3}$;

Sinter output $=41,893+6,876 \mathrm{Zh}-12,168 \mathrm{WK}-$

$5,587 L T-0,1724 Z h^{2}-0,55 W K^{2}-0,1749 L T^{2}$

$+0,4527 \mathrm{ZhWK}-0,0114 \mathrm{ZhLT}+0,8013 \mathrm{WKLT}$;

The resulting regression equations were adequate, since the calculated Fisher test was less than the theoretical one. Based on the equations on the program, a response surface and horizontal sections were obtained.

Table 3: Plan and Results of Experiments

\begin{tabular}{|c|c|c|c|c|c|c|c|c|c|c|}
\hline \multirow[t]{2}{*}{ No. } & \multicolumn{3}{|c|}{ Coded form } & \multicolumn{3}{|c|}{ Natural form } & \multicolumn{2}{|c|}{ Sinter strength, MPa } & \multicolumn{2}{|c|}{ Sinter output, \% } \\
\hline & $x_{1}$ & $\mathrm{X}_{2}$ & $\mathrm{X}_{3}$ & $\mathrm{Zh}$ & WK & LT & $\begin{array}{l}\text { Experiment } \\
\text { result }\end{array}$ & $\begin{array}{l}\text { Calculated } \\
\text { result }\end{array}$ & $\begin{array}{l}\text { Experiment } \\
\text { result }\end{array}$ & $\begin{array}{l}\text { Calculated } \\
\text { result }\end{array}$ \\
\hline 1 & + & + & + & 35,9 & 12,97 & 13,67 & 1,84 & 1,74 & 55,1 & 53,28 \\
\hline 2 & - & + & + & 24,1 & 12,97 & 13,67 & 1,63 & 1,64 & 30,6 & 27,68 \\
\hline 3 & + & - & + & 35,9 & 7,02 & 13,67 & 1,96 & 1,90 & 29,4 & 30,15 \\
\hline 4 & - & - & + & 24,1 & 7,02 & 13,67 & 1,80 & 1,78 & 32,1 & 35,50 \\
\hline 5 & + & + & - & 35,9 & 12,97 & 6,33 & 1,92 & 1,98 & 49,8 & 47,70 \\
\hline 6 & - & + & - & 24,1 & 12,97 & 6,33 & 1,01 & 1,10 & 19,6 & 20,05 \\
\hline 7 & + & - & - & 35,9 & 7,02 & 6,33 & 2,9 & 2,93 & 55,4 & 58,57 \\
\hline 8 & - & - & - & 24,1 & 7,02 & 6,33 & 1,89 & 2,03 & 61,8 & 62,91 \\
\hline 9 & $+1,7$ & 0 & 0 & 40 & 10 & 10 & 2,38 & 2,44 & 48,0 & 47,57 \\
\hline 10 & $-1,68$ & 0 & 0 & 20 & 10 & 10 & 1,71 & 1,60 & 30,1 & 28,74 \\
\hline 11 & 0 & $+1,68$ & 0 & 30 & 15 & 10 & 1,36 & 1,35 & 30,6 & 33,75 \\
\hline 12 & 0 & $-1,68$ & 0 & 30 & 5 & 10 & 2,30 & 2,26 & 55,0 & 49,54 \\
\hline 13 & 0 & 0 & $+1,68$ & 30 & 10 & 16 & 1,53 & 1,63 & 41,6 & 40,61 \\
\hline 14 & 0 & 0 & $-1,68$ & 30 & 10 & 4 & 2,20 & 2,03 & 59,4 & 55,4 \\
\hline 15 & 0 & 0 & 0 & 30 & 10 & 10 & 1,93 & 1,87 & 55,4 & 55,4 \\
\hline 16 & 0 & 0 & 0 & 30 & 10 & 10 & 1,84 & 1,87 & 55,0 & 55,4 \\
\hline 17 & 0 & 0 & 0 & 30 & 10 & 10 & 1,80 & 1,87 & 52,1 & 55,4 \\
\hline 18 & 0 & 0 & 0 & 30 & 10 & 10 & 2,03 & 1,87 & 56,6 & 55,4 \\
\hline 19 & 0 & 0 & 0 & 30 & 10 & 10 & 1,74 & 1,87 & 58,0 & 55,4 \\
\hline 20 & 0 & 0 & 0 & 30 & 10 & 10 & 1,95 & 1,87 & 57,1 & 55,4 \\
\hline
\end{tabular}


Thus, when the content of West Kamys ore in the sintering mixture is $8 \%, 4 \%$ of coal mining waste increase the content of Zhomart ore from 20 to $40 \%$, can increase the strength of sinter from 1,6 to $3,7 \mathrm{MPa}$. When the content of coal waste in the sintering mixture is $4 \%$, the sinter strength of 2 to 4 $\mathrm{MPa}$ can be obtained in the plane $\mathrm{A}^{\prime} \mathrm{ABC}$, i.e. when the content of Zhomart ore in the sintering mixture is from 2 to $4 \%$, and West Kamys ore is from 5 to $15 \%$. The figure shows that increasing the amount of waste coal reduces the strength of the sinter. And when the sintering mixture contains in $16 \%$ of coal waste, the sinter strength $>2 \mathrm{MPa}$ cannot be obtained.

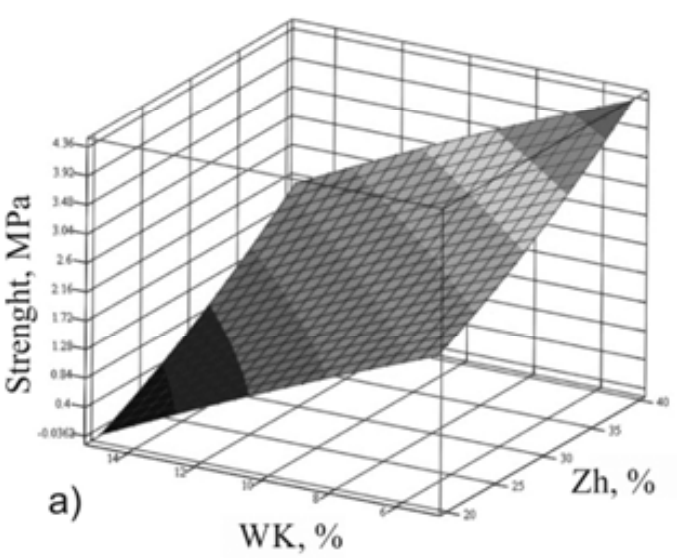

The pictures 1-5 demonstrate areas D'DÅF (6.3\% of the waste coal), G'GHI (10\% of the waste coal), in which the strength of the sinter is $>2 \mathrm{MPa}$. The impact of coal mining waste on the strength of the sinter can be seen from the following data for the content of Zhomart and West Kamys ores in the center of the plan. (i.e. 30 and $10 \%$, respectively).

\section{DISCUSSION}

There was investigated the possibility of joint agglomeration of sub-standard phosphatic and manganese ores with use of cheap fuel waste of the coal industry mixed with coke. The content

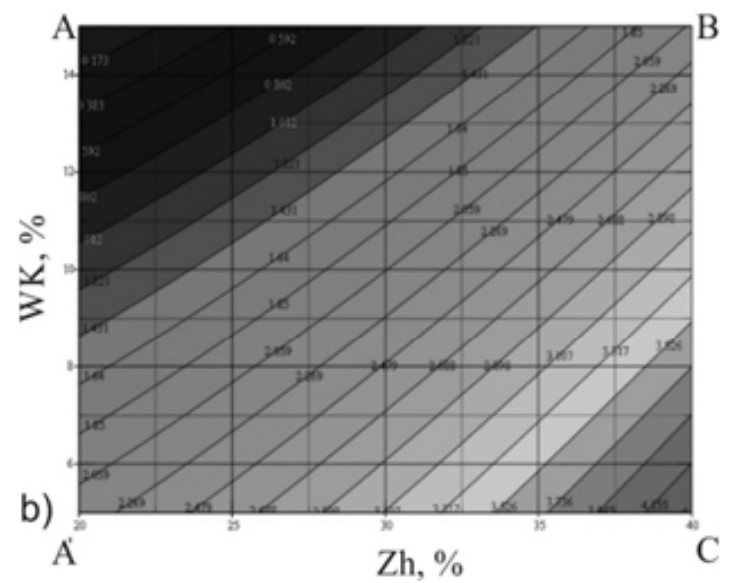

Fig. 1: Impact of amount of Zhomart (Zh) and West Kamys (WK) ores on the shape of the response surface (à, sinter density) and horizontal sections $(b)$, as a content in sintering mixture with $4 \%$ coal waste
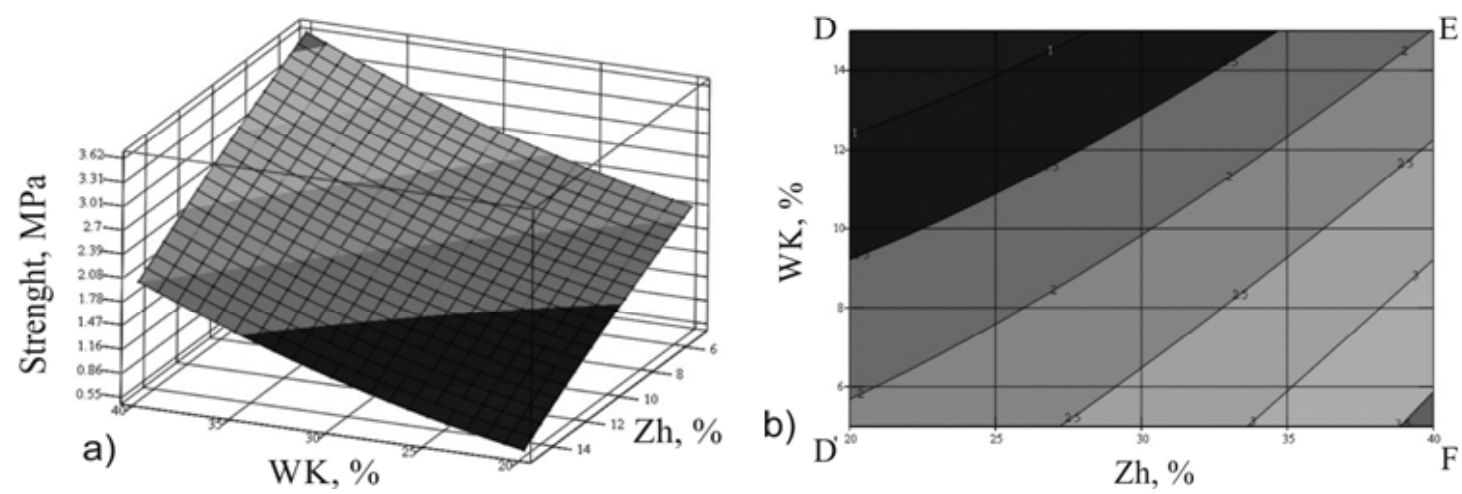

Fig. 2: Impact of amount of Zhomart (Zh) and West Kamys (WK) ores on the shape of the response surface (à, sinter density) and horizontal sections (b), as a content in sintering mixture with $6.3 \%$ coal waste 
of manganese which at electric melting transfers into a ferrophosphorus is increased in the obtained sinter. Further the ferrophosphorus can be used for producing the alloy, alloyed by manganese.

Tailored composition of sinter-feed mixture is determined by method of planning of experiments: $55-67 \%$ of phosphoritic fines; $3-17 \%$ of sub-standard manganese ores; $4-6,3 \%$ of waste of coal mining; $3-5 \%$ of solid fuel (fines of metallurgical coke) and $14-16 \%$ of sinter returns. This composition of sintering mixture allows to increase an yield of sinter in the process of agglomeration.

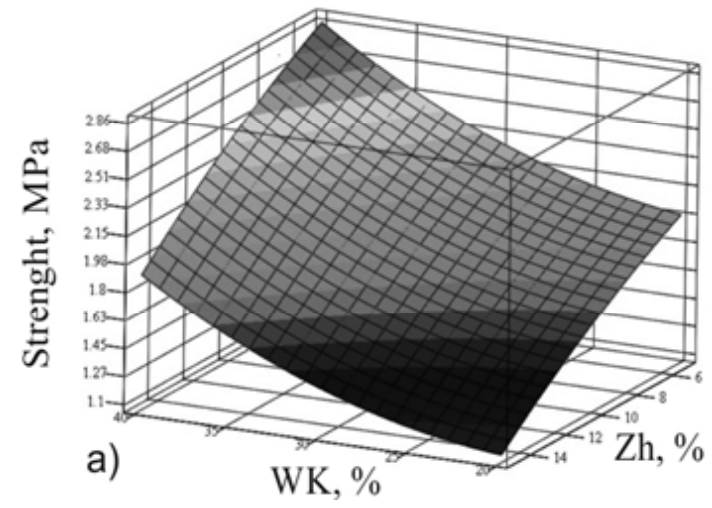

The above mentioned tailored composition of sintering mixture is characterized by the following parameters:

- height of bed- $20 \mathrm{~mm}$;

- bed depth of the loaded sintering mixture - 20 $\mathrm{mm}$;

- heat and gas release rate - 13,4-14,1 $\mathrm{nm}^{3} / \mathrm{t}$;

- air-flow rate- $150-155 \mathrm{~nm}^{3} / \mathrm{t}$.

Results of test for sinter strength are the following:

- narrowing-120-220 kg/piece;

- blow- $80-85 \%$ (by size yield $+5 \mathrm{~mm}$ );

- bucking- 5-8\% (by size yield - 0,5 $\mathrm{mm}$ ).

Fig. 3: Impact of amount of Zhomart (Zh) and West Kamys (WK) ores on the shape of the response surface (à, sinter density) and horizontal sections(b), as a content in sintering mixture with $10 \%$ coal waste

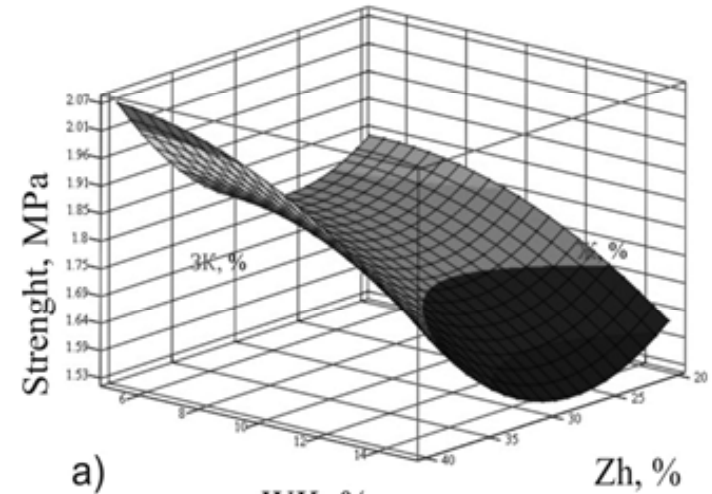

WK, \%

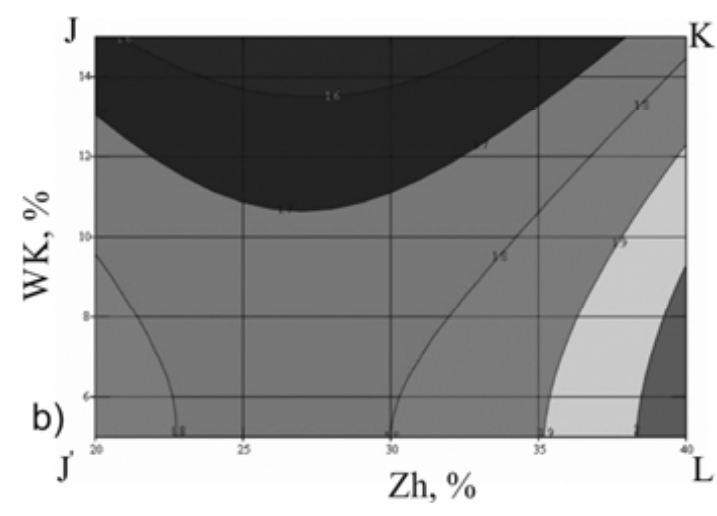

Fig. 4: Impact of amount of Zhomart (Zh) and West Kamys (WK) ores on the shape of the response surface (à, sinter density) and horizontal sections(b), as a content in sintering mixture with $13.6 \%$ coal waste 
Table 4: The Impact Of Content Of Coal Miningwaste In Sintering Mixture On Sinter Strength

\begin{tabular}{lccccc}
\hline Amount of coal waste, \% & 4,0 & 6,3 & 10 & 13,7 & 16,0 \\
Sinter strength, MPa & 2,27 & 2,1 & 1,95 & 1,86 & 1,62 \\
\hline
\end{tabular}
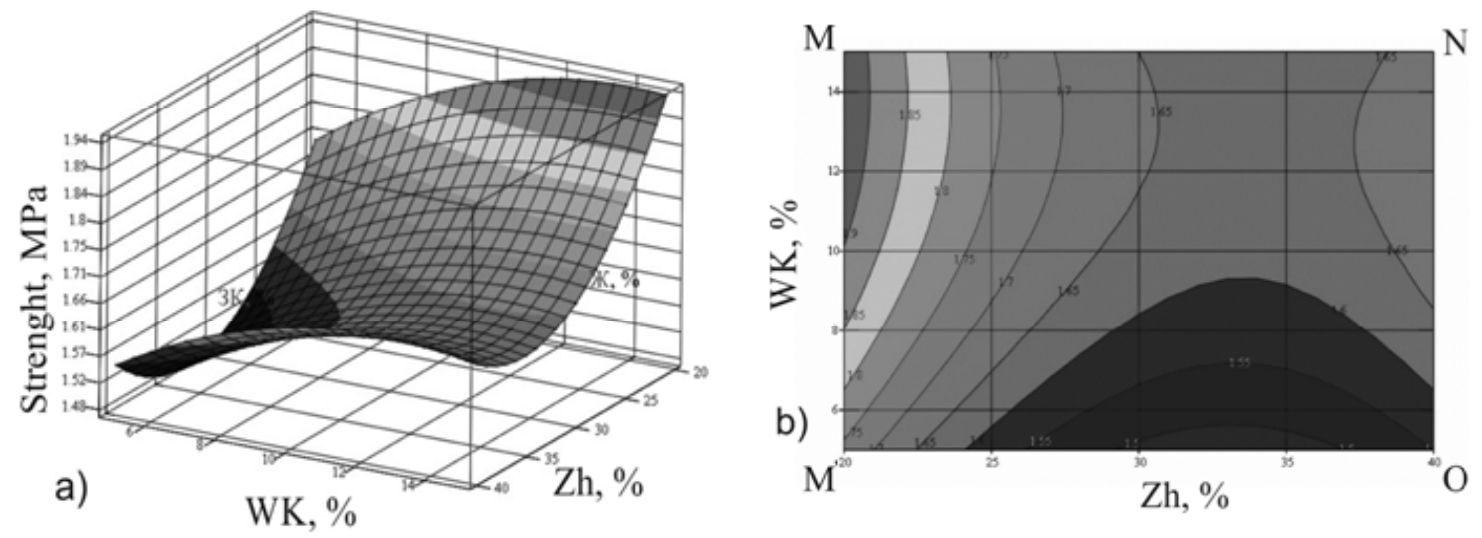

Fig. 5: Impact of amount of Zhomart (Zh) and West Kamys (WK) ores on the shape of the response surface (à, sinter density) and horizontal sections (b), as a content in sintering mixture with $16 \%$ coal waste

Module of acidity in sintering mixture which determines the tailored composition of the sinter mixture is $0,81-0,99$.

Table 4 shows the information about the impact of the coal miningwaste content in sintering mixture on the sinter strength.

According to the table 4 the rising amount of coal waste from 4,0 to $16,0 \%$ gives the result as to reduce the sinter strength. Therefore, to obtain sufficiently hard sinter, the content of coal mining waste in the sintering mixture is recommended to limit the range $4-6,3 \%$.

At obtained sinter electrofusion the significant part of $\mathrm{Mn}, \mathrm{Fe}$ and $\mathrm{P}$ transferred from sinter into ferroalloy, increasing the content of these components in it. Modulus of acidity is increased from 0,7 to 0,9 at increasing the manganese ore content of the East Kamys in the sintering mixture from 1,0 to $8,0 \%$. Reducing of transfer degree of manganese in the alloy is related to the formation of silicates such as $2 \mathrm{MnO} \cdot \mathrm{SiO}_{2}$ and $\mathrm{MnO} \cdot \mathrm{SiO}_{2}$ of $\mathrm{MnO}+\mathrm{SiO}_{2}$. Deoxidization of $\mathrm{P}_{2} \mathrm{O}_{5}$ carries out at a lower speed than the MnO. Thus, the phosphorus deoxidization degree and its transfer into the alloy is increased with the rising of the acidity module in sintering mixture.

The ferroalloy prepared from the sintering mixture which contains $20-56 \%$ of manganese, $8-23 \%$ of phosphorite, $3-15 \%$ of silica and $24-70 \%$ of iron, and it allows to decrease consumption of carboniferous agent to obtain the alloyed components.

\section{CONCLUSIONS}

The conducted researches allow determining the optimal ratio of the mixture components, composed on the basis of the content of phosphate and manganese ores, and wastes of coal mining.

There was determined the influence of the sintering mixture on the technological parameters of the sintering process.

It was established that at increasing of the content of coal mining waste in sintering mixture from 4 to $16 \%$, the strength of sinters decreases. 
Therefore, it should be considered that the content of coal mining waste from 4,0 to $16 \%$ is the tailored composition of sintering mixture.
Thus, it is established that the basic possibility of obtaining of high-quality sinters which in the further can be used at reception of ferro alloys for manufacture of high-hardness steels.

\section{REFERENCES}

1. Svyatov, B.A. Formation and development of Manganese industry of Kazakhstan. Almaty, RK, 2002, 416.

2. Berdyshev, E.Zh. Development of agglomeration technology of fine and roughly dispersed manganese ore. Science and Technics of Kazakhstan. 2011, 17-20.

3. Proceedings of the International Conference «Phosphates 2006», 23-24 April, Brussels, Belgium, 2006, 99.

4. Phosphates in XXI century: monograph / under editorship of Kiperman, Y.A. 2006, 208.

5. Kabdrakhmanova, S. Development of research on processing of phosphate Karatau. Poisk. The Series of natural and technical sciences. 2003,.4, 31-36.

6. Takenov, T.; Tolymbek, M.Zh. The development of the ferroalloy industry. Industry of Kazakhstan. 2003,.9, 48-57.

7. Fruinsky, M.I.;Bugs, V. I. Production of complex ferroalloys from mineral raw materials of Kazakhstan. Almaty: Science, 1998, 208.

8. Kunayev A.M.; Shumakov N.S. Agglomeration of small fractions of phosphorites of Karatau of use in production of phosphorus. Complex use of mineral raw materials. 1978,. 4, 3-7.

9. Edilbayev, A.I. Development of concept poor and non-conditional ores of Kazakhstan Republic. Marksheidery and Grounduse, 2011, 3, 23-26.

10. Gasik, V.I. Manganese. Moscow: Metallurgy, 1992, 608

11. Korotich, V.I. Agglomeration of ore materials. The scientific edition. Yekaterinburg. USTUUPI, 2003, 400 .
12. Agglomeration of ore materials. Scientific publication / under editorship of Korotich, B. Yekaterinburg, 2003, 400 .

13. Tsinadze, P.Sh. Smelting of limit silicomanganese with use of low-phosphoritic concentrates. Steel. 1991,.6, 39-41.

14. Tleuov, A.S.; Shevko, V.M. Sintering mixture for the production of manganese containing sinter. The Republic of Kazakhstan Patent, No.25101, class C22B 2/16. 2011.

15. Tleuov A.S.; Tleuova S.T. Modeling of the production process of manganese-containing fluxed phosphate sinter. Proceedings of the International Scientific Conference "Actual Issues of the Modern Science», loscow, Russia. 31 January, 2012, 410-414.

16. Computer modeling by optimization of technological processes of electrothermal productions. Collected scientific work "Electrothermy-2000". / under editorship of Udalov, Yu.P. Saint-Petersburg state technical university, Saint-Petersburg, 2000, 380.

17. Akhnazarova, S.L.; Gordnev, L.S. Mathematical modeling of extraction process of target components from natural raw materials. Chemical technology. 2005, 5, 33-35.

18. Akhnazarova, S.L. Modeling and optimization of chemical technological processes with the incomplete information on the mechanism. Textbook, Moscow: Russian chemicaltechnological university. 2010, 380.

19. Azam Marjani and other. Mathematical Modeling of Gas Separation in Flat-sheet Membrane Contactors. Orient J Chem 2015; 28 (1).13-18 